\title{
From metric spaces to partial metric spaces
}

\author{
Bessem Samet $^{1^{*}}$, Calogero Vetro ${ }^{2}$ and Francesca Vetro ${ }^{3}$
}

\section{"Correspondence:}

bessem.samet@gmail.com

${ }^{1}$ Department of Mathematics, King

Saud University, Riyadh, Saudi

Arabia

Full list of author information is

available at the end of the article

\begin{abstract}
Motivated by experience from computer science, Matthews (1994) introduced a nonzero self-distance called a partial metric. He also extended the Banach contraction principle to the setting of partial metric spaces. In this paper, we show that fixed point theorems on partial metric spaces (including the Matthews fixed point theorem) can be deduced from fixed point theorems on metric spaces. New fixed point theorems on metric spaces are established and analogous results on partial metric spaces are deduced.

MSC: $47 \mathrm{H} 10 ; 54 \mathrm{H} 25$
\end{abstract}

Keywords: metric space; partial metric space; fixed point

\section{Introduction and preliminaries}

Over the last decades, fixed point theory has been revealed as a very powerful tool in the study of nonlinear phenomena. In particular, fixed point techniques and results have been developed in pure and applied analysis, topology and geometry. A fundamental result of this theory is the well-known Banach contraction principle [1]. In the last fifty years, the Banach contraction principle has been extensively studied and generalized on many settings (see, for example, [2-12]). In the same decades, several authors worked on domain theory in order to equip semantics domain with the notion of distance. In 1994, Matthews [8] introduced the notion of partial metric space as a part of the study of denotational semantics of dataflow networks and showed that the Banach contraction principle can be generalized to the partial metric context for applications in program verification. Later on, many researchers studied fixed point theorems in partial metric spaces. For more details, the reader can refer to [13-22].

First, we start by recalling some basic definitions and properties of partial metric spaces.

Definition 1.1 (see [8]) A partial metric on a nonempty set $X$ is a function $p: X \times X \rightarrow$ $[0, \infty)$ such that for all $x, y, z \in X$,

$\left(\mathrm{p}_{1}\right) \quad x=y \Longleftrightarrow p(x, x)=p(x, y)=p(y, y)$;

$\left(\mathrm{p}_{2}\right) p(x, x) \leq p(x, y)$;

( $\left.\mathrm{p}_{3}\right) p(x, y)=p(y, x)$;

$\left(\mathrm{p}_{4}\right) p(x, y) \leq p(x, z)+p(z, y)-p(z, z)$.

A partial metric space is a pair $(X, p)$ such that $X$ is a nonempty set and $p$ is a partial metric on $X$.

(0) 2013 Samet et al.: licensee Springer. This is an Open Access article distributed under the terms of the Creative Commons Attribution License (http://creativecommons.org/licenses/by/2.0), which permits unrestricted use, distribution, and reproduction in any medium, provided the original work is properly cited. 
It is clear that if $p(x, y)=0$, then from $\left(\mathrm{p}_{1}\right)$ and $\left(\mathrm{p}_{2}\right), x=y$; but if $x=y, p(x, y)$ may not be 0 . A basic example of a partial metric space is the pair $([0, \infty), p)$, where $p(x, y)=\max \{x, y\}$ for all $x, y \in[0, \infty)$. Other examples of partial metric spaces which are interesting from a computational point of view may be found in [8]. We observe that each partial metric $p$ on $X$ generates a $T_{0}$ topology $\tau_{p}$ on $X$ which has as a base the family of open $p$-balls $\left\{B_{p}(x, \varepsilon): x \in X, \varepsilon>0\right\}$, where $B_{p}(x, \varepsilon)=\{y \in X: p(x, y)<p(x, x)+\varepsilon\}$ for all $x \in X$ and $\varepsilon>0$. If $p$ is a partial metric on $X$, then the function $p^{s}: X \times X \rightarrow[0, \infty)$ given by

$$
p^{s}(x, y)=2 p(x, y)-p(x, x)-p(y, y)
$$

is a metric on $X$.

Definition 1.2 (see [8]) Let $(X, p)$ be a partial metric space and $\left\{x_{n}\right\}$ be a sequence in $X$. Then

(i) $\left\{x_{n}\right\}$ converges to a point $x \in X$ if and only if $p(x, x)=\lim _{n \rightarrow+\infty} p\left(x, x_{n}\right)$. We may write this as $x_{n} \rightarrow x$

(ii) $\left\{x_{n}\right\}$ is called a Cauchy sequence if $\lim _{n, m \rightarrow+\infty} p\left(x_{n}, x_{m}\right)$ exists and is finite;

(iii) $(X, p)$ is said to be complete if every Cauchy sequence $\left\{x_{n}\right\}$ in $X$ converges, with respect to $\tau_{p}$, to a point $x \in X$ such that $p(x, x)=\lim _{n, m \rightarrow+\infty} p\left(x_{n}, x_{m}\right)$.

Lemma 1.1 (see [8]) Let $(X, p)$ be a partial metric space. Then

(a) $\left\{x_{n}\right\}$ is a Cauchy sequence in $(X, p)$ if and only if it is a Cauchy sequence in the metric space $\left(X, p^{s}\right)$;

(b) A partial metric space $(X, p)$ is complete if and only if the metric space $\left(X, p^{s}\right)$ is complete. Furthermore, $\lim _{n \rightarrow+\infty} p^{s}\left(x_{n}, x\right)=0$ if and only if

$$
p(x, x)=\lim _{n \rightarrow+\infty} p\left(x_{n}, x\right)=\lim _{n, m \rightarrow+\infty} p\left(x_{n}, x_{m}\right)
$$

In 2008, Rus [20] investigated the basic problems of metric fixed point theory in the case of partial metric spaces: existence and uniqueness, the convergence of successive approximations and well posedness of the fixed point problem. Consequently, he presented some interesting open questions: If $T:(X, p) \rightarrow(X, p)$ is a generalized contraction, which condition satisfies $T$ with respect to $p^{s}$ ? How to use fixed point theorems in a metric space $\left(X, p^{s}\right)$ to give analogous fixed point results in a partial metric space $(X, p)$ ?

In this paper, motivated and inspired by Rus [20], we present new fixed point theorems on complete metric spaces. As an application of our results, we show that the Matthews fixed point theorem on partial metric spaces is a particular case of our first theorem on complete metric spaces. Moreover, we obtain some useful corollaries in the setting of partial metric spaces. In so doing, we provide useful answers to the above open questions.

\section{New fixed point theorems on metric spaces}

In this section, we present new fixed point theorems on the setting of complete metric spaces. Our first result is the following.

Theorem 2.1 Let $(X, d)$ be a complete metric space, $\varphi: X \rightarrow[0, \infty)$ be a lower semicontinuous function and $T: X \rightarrow X$ be a given mapping. Suppose that for any $0<a<b<\infty$, 
there exists $0<\gamma(a, b)<1$ such that for all $x, y \in X$,

$$
\begin{aligned}
a & \leq d(x, y)+\varphi(x)+\varphi(y) \leq b \\
& \Longrightarrow d(T x, T y)+\varphi(T x)+\varphi(T y) \leq \gamma(a, b)[d(x, y)+\varphi(x)+\varphi(y)] .
\end{aligned}
$$

Then $T$ has a unique fixed point $x^{*} \in X$. Moreover, we have $\varphi\left(x^{*}\right)=0$.

Proof Let $x_{0}$ be an arbitrary point in $X$. Consider the sequence $\left\{x_{n}\right\} \subset X$ defined by $x_{n+1}=$ $T x_{n}$ for all $n \geq 0$.

Step I. We prove that

$$
d\left(x_{n-1}, x_{n}\right)+\varphi\left(x_{n-1}\right)+\varphi\left(x_{n}\right) \rightarrow 0 \quad \text { as } n \rightarrow \infty .
$$

If for some $n$ we have $d\left(x_{n-1}, x_{n}\right)+\varphi\left(x_{n-1}\right)+\varphi\left(x_{n}\right)=0$, then $x_{n-1}$ will be a fixed point of $T$. So, we can suppose that

$$
0<d\left(x_{n-1}, x_{n}\right)+\varphi\left(x_{n-1}\right)+\varphi\left(x_{n}\right), \quad \forall n \geq 1 .
$$

Suppose that for some $n_{0} \geq 1$,

$$
d\left(x_{n_{0}-1}, x_{n_{0}}\right)+\varphi\left(x_{n_{0}-1}\right)+\varphi\left(x_{n_{0}}\right)<d\left(x_{n_{0}}, x_{n_{0}+1}\right)+\varphi\left(x_{n_{0}}\right)+\varphi\left(x_{n_{0}+1}\right) .
$$

From (4) and (5), we have

$$
\begin{aligned}
0<a & :=d\left(x_{n_{0}-1}, x_{n_{0}}\right)+\varphi\left(x_{n_{0}-1}\right)+\varphi\left(x_{n_{0}}\right) \\
& \leq d\left(x_{n_{0}-1}, x_{n_{0}}\right)+\varphi\left(x_{n_{0}-1}\right)+\varphi\left(x_{n_{0}}\right) \\
& <d\left(x_{n_{0}}, x_{n_{0}+1}\right)+\varphi\left(x_{n_{0}}\right)+\varphi\left(x_{n_{0}+1}\right):=b .
\end{aligned}
$$

From (2), there exists $\gamma(a, b) \in(0,1)$ such that

$$
d\left(x_{n_{0}}, x_{n_{0}+1}\right)+\varphi\left(x_{n_{0}}\right)+\varphi\left(x_{n_{0}+1}\right) \leq \gamma(a, b)\left[d\left(x_{n_{0}-1}, x_{n_{0}}\right)+\varphi\left(x_{n_{0}-1}\right)+\varphi\left(x_{n_{0}}\right)\right] .
$$

From (4) and (5), we get

$$
0<d\left(x_{n_{0}-1}, x_{n_{0}}\right)+\varphi\left(x_{n_{0}-1}\right)+\varphi\left(x_{n_{0}}\right)<\gamma(a, b)\left[d\left(x_{n_{0}-1}, x_{n_{0}}\right)+\varphi\left(x_{n_{0}-1}\right)+\varphi\left(x_{n_{0}}\right)\right],
$$

which implies that $\gamma(a, b)>1$, a contradiction. Thus, our assumption (5) is wrong. We deduce that

$$
\mathcal{U}_{n}:=d\left(x_{n}, x_{n+1}\right)+\varphi\left(x_{n}\right)+\varphi\left(x_{n+1}\right) \leq \mathcal{U}_{n-1}:=d\left(x_{n-1}, x_{n}\right)+\varphi\left(x_{n-1}\right)+\varphi\left(x_{n}\right), \quad \forall n \geq 1
$$

This implies that $\left\{\mathcal{U}_{n}\right\}$ is a non-increasing sequence of positive real numbers. Hence, there is $r \geq 0$ such that

$$
d\left(x_{n-1}, x_{n}\right)+\varphi\left(x_{n-1}\right)+\varphi\left(x_{n}\right) \rightarrow r^{+} \text {as } n \rightarrow \infty \text {. }
$$


Suppose that $r>0$. Then $0<r \leq d\left(x_{n-1}, x_{n}\right)+\varphi\left(x_{n-1}\right)+\varphi\left(x_{n}\right) \leq \mathcal{U}_{0}$ for all $n \geq 1$. From (2), there exists $\gamma\left(r, \mathcal{U}_{0}\right) \in(0,1)$ such that

$$
d\left(x_{n}, x_{n+1}\right)+\varphi\left(x_{n}\right)+\varphi\left(x_{n+1}\right) \leq \gamma\left(r, \mathcal{U}_{0}\right)\left[d\left(x_{n-1}, x_{n}\right)+\varphi\left(x_{n-1}\right)+\varphi\left(x_{n}\right)\right], \quad \forall n \geq 1
$$

Letting $n \rightarrow \infty$ in the above inequality and using (6), we get $r \leq \gamma\left(r, \mathcal{U}_{0}\right) r$, which implies that $\gamma\left(r, \mathcal{U}_{0}\right) \geq 1$, a contradiction. Thus, $r=0$ and (3) holds.

Step II. We prove that $\left\{x_{n}\right\}$ is a Cauchy sequence in $(X, d)$.

Suppose that $\left\{x_{n}\right\}$ is not a Cauchy sequence. Then there exists $\varepsilon>0$ for which we can find two sequences of positive integers $\{m(k)\}$ and $\{n(k)\}$ such that for all positive integer $k$,

$$
n(k)>m(k)>k, \quad d\left(x_{m(k)}, x_{n(k)}\right) \geq \varepsilon, \quad d\left(x_{m(k)}, x_{n(k)-1}\right)<\varepsilon .
$$

From (7), we have

$$
\varepsilon \leq d\left(x_{n(k)}, x_{m(k)}\right) \leq d\left(x_{m(k)}, x_{n(k)-1}\right)+d\left(x_{n(k)-1}, x_{n(k)}\right)<\varepsilon+d\left(x_{n(k)}, x_{n(k)-1}\right) .
$$

Thus, for all $k$, we have

$$
\varepsilon \leq d\left(x_{n(k)}, x_{m(k)}\right)<\varepsilon+d\left(x_{n(k)}, x_{n(k)-1}\right) .
$$

Letting $k \rightarrow \infty$ in the above inequality and using (3), we obtain

$$
d\left(x_{n(k)}, x_{m(k)}\right) \rightarrow \varepsilon^{+} \quad \text { as } k \rightarrow \infty .
$$

On the other hand, we have

$$
d\left(x_{n(k)}, x_{m(k)}\right) \leq d\left(x_{n(k)}, x_{n(k)+1}\right)+d\left(x_{n(k)+1}, x_{m(k)+1}\right)+d\left(x_{m(k)+1}, x_{m(k)}\right)
$$

and

$$
d\left(x_{n(k)+1}, x_{m(k)+1}\right) \leq d\left(x_{n(k)+1}, x_{n(k)}\right)+d\left(x_{n(k)}, x_{m(k)}\right)+d\left(x_{m(k)}, x_{m(k)+1}\right) .
$$

Thus, we have

$$
\left|d\left(x_{n(k)+1}, x_{m(k)+1}\right)-d\left(x_{n(k)}, x_{m(k)}\right)\right| \leq d\left(x_{n(k)+1}, x_{n(k)}\right)+d\left(x_{m(k)}, x_{m(k)+1}\right) .
$$

Letting $k \rightarrow \infty$ in the above inequality, using (3) and (8), we obtain that

$$
d\left(x_{n(k)+1}, x_{m(k)+1}\right) \rightarrow \varepsilon \quad \text { as } k \rightarrow \infty .
$$

On the other hand, for all $k$, we have

$$
\begin{aligned}
\varepsilon & \leq d\left(x_{n(k)}, x_{m(k)}\right)+\varphi\left(x_{n(k)}\right)+\varphi\left(x_{m(k)}\right) \\
& \leq d\left(x_{m(k)}, x_{n(k)-1}\right)+d\left(x_{n(k)-1}, x_{n(k)}\right)+\Phi \leq \varepsilon+\mathcal{U}_{0}+\Phi,
\end{aligned}
$$


where $\Phi$ is the upper bound of $\left\{2 \varphi\left(x_{n}\right)\right\}$ (note that from (3), $\varphi\left(x_{n}\right) \rightarrow 0$ as $n \rightarrow \infty$ ). Applying (2), we obtain that there exists $\gamma\left(\varepsilon, \varepsilon+\mathcal{U}_{0}+\Phi\right) \in(0,1)$ such that

$$
\begin{aligned}
& d\left(x_{n(k)+1}, x_{m(k)+1}\right)+\varphi\left(x_{n(k)+1}\right)+\varphi\left(x_{m(k)+1}\right) \\
& \quad \leq \gamma\left(\varepsilon, \varepsilon+\mathcal{U}_{0}+\Phi\right)\left[d\left(x_{n(k)}, x_{m(k)}\right)+\varphi\left(x_{n(k)}\right)+\varphi\left(x_{m(k)}\right)\right]
\end{aligned}
$$

for all $k$. Letting $k \rightarrow \infty$ in the above inequality, using (3), (8) and (9), we obtain that $\varepsilon \leq \gamma\left(\varepsilon, \varepsilon+\mathcal{U}_{0}+\Phi\right) \varepsilon$, which implies that $\gamma\left(\varepsilon, \varepsilon+\mathcal{U}_{0}+\Phi\right) \geq 1$, a contradiction with $\gamma(\varepsilon, \varepsilon+$ $\left.\mathcal{U}_{0}+\Phi\right) \in(0,1)$. Hence, we deduce that $\left\{x_{n}\right\}$ is a Cauchy sequence in $(X, d)$. Since $(X, d)$ is complete, there exists $x^{*} \in X$ such that $x_{n} \rightarrow x^{*}$ as $n \rightarrow \infty$.

Step III. We prove that

$$
\varphi\left(x^{*}\right)=0
$$

From (3), we have $\varphi\left(x_{n}\right) \rightarrow 0$ as $n \rightarrow \infty$. Since $\varphi$ is lower semi-continuous, it follows that

$$
0 \leq \varphi\left(x^{*}\right) \leq \liminf _{n \rightarrow+\infty} \varphi\left(x_{n}\right)=\lim _{n \rightarrow+\infty} \varphi\left(x_{n}\right)=0,
$$

which implies (10).

Step $I V$. We prove that $x^{*}$ is a fixed point of $T$. Consider the sets $I, J \subseteq \mathbb{N}$ defined by

$$
I:=\left\{n \in \mathbb{N}: x_{n}=x^{*}\right\} \text { and } J:=\left\{n \in \mathbb{N}: x_{n} \neq x^{*}\right\} .
$$

As $I \cup J=\mathbb{N}$, at least one of these subsets is infinite. So, we consider two cases.

Case 1.I is an infinite subset. In this case, we can find a subsequence $\left\{x_{n(p)}\right\}$ of $\left\{x_{n}\right\}$ such that $x_{n(p)}=x^{*}$ for all $p$. Since $x_{n(p)+1}=T x_{n(p)}=T x^{*}$ and $x_{n(p)+1} \rightarrow x^{*}$ as $p \rightarrow \infty$, we have necessarily $x^{*}=T x^{*}$, that is, $x^{*}$ is a fixed point of $T$.

Case 2. $J$ is an infinite subset. In this case, we can find a subsequence $\left\{x_{n(p)}\right\}$ of $\left\{x_{n}\right\}$ such that $d\left(x_{n(p)}, x^{*}\right)>0$ for all $p$. Then, for every $p$, we can find $0<A_{p}<B_{p}$ such that

$$
A_{p} \leq d\left(x_{n(p)}, x^{*}\right)+\varphi\left(x_{n(p)}\right)+\varphi\left(x^{*}\right) \leq B_{p} .
$$

From (2), we have

$$
d\left(x_{n(p)+1}, T x^{*}\right)+\varphi\left(x_{n(p)+1}\right)+\varphi\left(T x^{*}\right) \leq \gamma\left(A_{p}, B_{p}\right)\left[d\left(x_{n(p)}, x^{*}\right)+\varphi\left(x_{n(p)}\right)+\varphi\left(x^{*}\right)\right] .
$$

Since $\gamma\left(A_{p}, B_{p}\right)<1$, for all $p$ we deduce that

$$
d\left(x_{n(p)+1}, T x^{*}\right)+\varphi\left(x_{n(p)+1}\right)+\varphi\left(T x^{*}\right) \leq d\left(x_{n(p)}, x^{*}\right)+\varphi\left(x_{n(p)}\right)+\varphi\left(x^{*}\right) .
$$

Since $d\left(x_{n(p)}, x^{\prime \prime}\right)+\varphi\left(x_{n(p)}\right)+\varphi\left(x^{*}\right) \rightarrow \varphi\left(x^{*}\right)=0$ as $p \rightarrow+\infty$ (see (3) and (10)), letting $p \rightarrow$ $+\infty$ in the above inequality, we obtain that

$$
\lim _{p \rightarrow+\infty} d\left(x_{n(p)+1}, T x^{*}\right)+\varphi\left(T x^{*}\right) \leq 0
$$

and so $x_{n(p)+1} \rightarrow T x^{*}$ as $p \rightarrow+\infty$. By the uniqueness of the limit, we have necessarily $x^{*}=$ $T x^{*}$. Then $x^{*}$ is a fixed point of $T$. 
Step $V$. Uniqueness of the fixed point. Suppose that $y^{\prime \prime} \in X$ is another fixed point of $T$, that is, $T y^{\prime \prime}=y^{\prime \prime}$ and $d\left(x^{\prime \prime}, y^{\prime \prime}\right)>0$. Since $d\left(x^{*}, y^{*}\right)>0$, we can find $0<\alpha<\beta$ such that $\alpha \leq$ $d\left(x^{*}, y^{*}\right)+\varphi\left(x^{*}\right)+\varphi\left(y^{*}\right) \leq \beta$. From (2), we have

$$
d\left(T x^{*}, T y^{*}\right)+\varphi\left(T x^{*}\right)+\varphi\left(T y^{*}\right) \leq \gamma(\alpha, \beta)\left[d\left(x^{*}, y^{*}\right)+\varphi\left(x^{*}\right)+\varphi\left(y^{*}\right)\right],
$$

that is,

$$
d\left(x^{*}, y^{*}\right)+\varphi\left(x^{*}\right)+\varphi\left(y^{*}\right) \leq \gamma(\alpha, \beta)\left[d\left(x^{*}, y^{*}\right)+\varphi\left(x^{*}\right)+\varphi\left(y^{*}\right)\right]
$$

which implies that $\gamma(\alpha, \beta) \geq 1$, a contradiction with $\gamma(\alpha, \beta) \in(0,1)$. Then $x^{*}$ is the unique fixed point of $T$. This makes end to the proof.

An immediate consequence of Theorem 2.1 is the following.

Theorem 2.2 Let $(X, d)$ be a complete metric space, $\varphi: X \rightarrow[0, \infty)$ be a lower semicontinuous function and $T: X \rightarrow X$ be a given mapping. Suppose that there exists a constant $\gamma \in(0,1)$ such that for all $x, y \in X$,

$$
d(T x, T y)+\varphi(T x)+\varphi(T y) \leq \gamma[d(x, y)+\varphi(x)+\varphi(y)] .
$$

Then $T$ has a unique fixed point $x^{*} \in X$. Moreover, we have $\varphi\left(x^{*}\right)=0$.

Remark 2.1 Taking $\varphi \equiv 0$ in Theorem 2.2, we obtain the Banach contraction principle.

The following result is a generalization of Kannan's fixed point theorem.

Theorem 2.3 Let $(X, d)$ be a complete metric space, $\varphi: X \rightarrow[0, \infty)$ be a lower semicontinuous function and $T: X \rightarrow X$ be a given mapping. Suppose that there exists a constant $\gamma \in(0,1 / 2)$ such that for all $x, y \in X$,

$$
d(T x, T y)+\varphi(T x)+\varphi(T y) \leq \gamma[d(x, T x)+d(y, T y)+\varphi(x)+\varphi(y)+\varphi(T x)+\varphi(T y)] .
$$

Then $T$ has a unique fixed point $x^{*} \in X$. Moreover, we have $\varphi\left(x^{*}\right)=0$.

Proof Let $x_{0} \in X$ be an arbitrary point. Define the sequence $\left\{x_{n}\right\}$ in $X$ by $x_{n+1}=T x_{n}$ for all $n \geq 0$. Applying (11) with $x=x_{1}$ and $y=x_{0}$, we get immediately

$$
d\left(x_{2}, x_{1}\right)+\varphi\left(x_{2}\right)+\varphi\left(x_{1}\right) \leq\left(\frac{\gamma}{1-\gamma}\right)\left[d\left(x_{1}, x_{0}\right)+\varphi\left(x_{1}\right)+\varphi\left(x_{0}\right)\right]
$$

Continuing this process, by induction, we obtain that

$$
d\left(x_{n+1}, x_{n}\right)+\varphi\left(x_{n+1}\right)+\varphi\left(x_{n}\right) \leq\left(\frac{\gamma}{1-\gamma}\right)^{n}\left[d\left(x_{1}, x_{0}\right)+\varphi\left(x_{1}\right)+\varphi\left(x_{0}\right)\right]
$$

for all $n \geq 0$. Note that since $\gamma \in(0,1 / 2)$, we have $\gamma /(1-\gamma) \in(0,1)$, so from inequality (12), the sequence $\left\{x_{n}\right\}$ is Cauchy in the metric space $(X, d)$. Since $(X, d)$ is a complete metric 
space, there exists $x^{\prime \prime} \in X$ such that $x_{n} \rightarrow x^{*}$ as $n \rightarrow \infty$. On the other hand, from (12), we have

$$
\varphi\left(x_{n}\right) \leq\left(\frac{\gamma}{1-\gamma}\right)^{n}\left[d\left(x_{1}, x_{0}\right)+\varphi\left(x_{1}\right)+\varphi\left(x_{0}\right)\right]
$$

for all $n \geq 0$. Letting $n \rightarrow+\infty$ in the above inequality, we get $\varphi\left(x_{n}\right) \rightarrow 0$ as $n \rightarrow \infty$. Since $\varphi$ is lower semi-continuous, it follows that

$$
0 \leq \varphi\left(x^{*}\right) \leq \liminf _{n \rightarrow+\infty} \varphi\left(x_{n}\right)=\lim _{n \rightarrow+\infty} \varphi\left(x_{n}\right)=0
$$

that is, $\varphi\left(x^{*}\right)=0$. Now, we prove that $x^{*}$ is a fixed point of $T$. Indeed, applying condition (11), we obtain that

$$
\begin{aligned}
& d\left(x_{n+1}, T x^{*}\right)+\varphi\left(x_{n+1}\right)+\varphi\left(T x^{*}\right) \\
& \quad \leq \gamma\left[d\left(x_{n}, x_{n+1}\right)+d\left(x^{*}, T x^{*}\right)+\varphi\left(x_{n}\right)+\varphi\left(x^{*}\right)+\varphi\left(x_{n+1}\right)+\varphi\left(T x^{*}\right)\right]
\end{aligned}
$$

for all $n \geq 0$. Letting $n \rightarrow \infty$, we obtain

$$
d\left(x^{*}, T x^{*}\right)+\varphi\left(T x^{*}\right) \leq \gamma\left[d\left(x^{*}, T x^{*}\right)+\varphi\left(T x^{*}\right)\right]
$$

which implies (since $0<\gamma<1 / 2$ ) that

$$
d\left(x^{*}, T x^{*}\right)=\varphi\left(T x^{*}\right)=0,
$$

that is, $x^{*}=T x^{*}$.

Suppose now that $y^{\prime \prime}$ is another fixed point of $T$. Applying (11) with $x=y=y^{\prime \prime}$, we obtain

$$
\varphi\left(y^{*}\right) \leq 2 \gamma \varphi\left(y^{*}\right)
$$

which implies (since $0<\gamma<1 / 2$ ) that $\varphi\left(y^{*}\right)=0$. Now, applying (11) with $x=x^{*}$ and $y=y^{*}$, taking into consideration that $\varphi\left(x^{*}\right)=\varphi\left(y^{*}\right)=0$, we obtain $d\left(x^{*}, y^{*}\right)=0$, which implies that $x^{*}=y^{*}$.

Remark 2.2 Taking $\varphi \equiv 0$ in Theorem 2.3, we obtain Kannan's fixed point theorem [6].

Now, we state and prove a generalization of Reich's fixed point theorem.

Theorem 2.4 Let $(X, d)$ be a complete metric space, $\varphi: X \rightarrow[0, \infty)$ be a lower semicontinuous function and $T: X \rightarrow X$ be a given mapping. Suppose that there exist $\alpha, \beta, \gamma \in$ $[0, \infty)$, with $\alpha+\beta+\gamma<1$, such that

$$
\begin{aligned}
d(T x, T y)+\varphi(T x)+\varphi(T y) \leq & \alpha[d(x, y)+\varphi(x)+\varphi(y)]+\beta[d(x, T x)+\varphi(x)+\varphi(T x)] \\
& +\gamma[d(y, T y)+\varphi(y)+\varphi(T y)]
\end{aligned}
$$

for all $x, y \in X$. Then $T$ has a unique fixed point $x^{*} \in X$. Moreover, we have $\varphi\left(x^{*}\right)=0$. 
Proof Let $x_{0} \in X$ be an arbitrary point. Define the sequence $\left\{x_{n}\right\}$ in $X$ by $x_{n+1}=T x_{n}$ for all $n \geq 0$. Applying (13) with $x=x_{1}$ and $y=x_{0}$, using the triangular inequality, we have

$$
\begin{aligned}
d\left(x_{2}, x_{1}\right)+\varphi\left(x_{2}\right)+\varphi\left(x_{1}\right) \leq & \alpha\left[d\left(x_{1}, x_{0}\right)+\varphi\left(x_{1}\right)+\varphi\left(x_{0}\right)\right]+\beta\left[d\left(x_{2}, x_{1}\right)+\varphi\left(x_{1}\right)+\varphi\left(x_{2}\right)\right] \\
& +\gamma\left[d\left(x_{1}, x_{0}\right)+\varphi\left(x_{0}\right)+\varphi\left(x_{1}\right)\right] .
\end{aligned}
$$

This implies that

$$
d\left(x_{2}, x_{1}\right)+\varphi\left(x_{2}\right)+\varphi\left(x_{1}\right) \leq\left(\frac{\alpha+\gamma}{1-\beta}\right)\left[d\left(x_{1}, x_{0}\right)+\varphi\left(x_{1}\right)+\varphi\left(x_{0}\right)\right]
$$

where $(\alpha+\gamma) /(1-\beta) \in(0,1)$. Continuing this process, by induction, we obtain that

$$
d\left(x_{n+1}, x_{n}\right)+\varphi\left(x_{n+1}\right)+\varphi\left(x_{n}\right) \leq\left(\frac{\alpha+\gamma}{1-\beta}\right)^{n}\left[d\left(x_{1}, x_{0}\right)+\varphi\left(x_{1}\right)+\varphi\left(x_{0}\right)\right]
$$

for all $n \geq 0$. The rest of the proof is similar to the proof of Theorem 2.3.

Remark 2.3 Taking $\varphi \equiv 0$ in Theorem 2.4, we obtain Reich's fixed point theorem [10].

Now, we give a generalization of Chatterjea's fixed point theorem.

Theorem 2.5 Let $(X, d)$ be a complete metric space, $\varphi: X \rightarrow[0, \infty)$ be a lower semicontinuous function and $T: X \rightarrow X$ be a given mapping. Suppose that there exists a constant $k \in(0,1 / 2)$ such that

$$
d(T x, T y)+\varphi(T x)+\varphi(T y) \leq k[d(x, T y)+d(y, T x)+\varphi(x)+\varphi(y)+\varphi(T x)+\varphi(T y)]
$$

for all $x, y \in X$. Then $T$ has a unique fixed point $x^{*} \in X$. Moreover, we have $\varphi\left(x^{*}\right)=0$.

Proof Let $x_{0} \in X$ be an arbitrary point. Define the sequence $\left\{x_{n}\right\}$ in $X$ by $x_{n+1}=T x_{n}$ for all $n \geq 0$. Applying (14) with $x=x_{1}$ and $y=x_{0}$, using the triangular inequality, we have

$$
\begin{aligned}
d\left(x_{2}, x_{1}\right)+\varphi\left(x_{2}\right)+\varphi\left(x_{1}\right) & \leq k\left[d\left(x_{1}, x_{1}\right)+d\left(x_{0}, x_{2}\right)+\varphi\left(x_{1}\right)+\varphi\left(x_{0}\right)+\varphi\left(x_{2}\right)+\varphi\left(x_{1}\right)\right] \\
& \leq k\left[d\left(x_{0}, x_{1}\right)+d\left(x_{1}, x_{2}\right)+\varphi\left(x_{1}\right)+\varphi\left(x_{0}\right)+\varphi\left(x_{2}\right)+\varphi\left(x_{1}\right)\right] .
\end{aligned}
$$

This implies that

$$
d\left(x_{2}, x_{1}\right)+\varphi\left(x_{2}\right)+\varphi\left(x_{1}\right) \leq\left(\frac{k}{1-k}\right)\left[d\left(x_{1}, x_{0}\right)+\varphi\left(x_{1}\right)+\varphi\left(x_{0}\right)\right] .
$$

Continuing this process, by induction, we obtain that

$$
d\left(x_{n+1}, x_{n}\right)+\varphi\left(x_{n+1}\right)+\varphi\left(x_{n}\right) \leq\left(\frac{k}{1-k}\right)^{n}\left[d\left(x_{1}, x_{0}\right)+\varphi\left(x_{1}\right)+\varphi\left(x_{0}\right)\right]
$$

for all $n \geq 0$. The rest of the proof is similar to the proof of Theorem 2.3. 
Remark 2.4 Taking $\varphi \equiv 0$ in Theorem 2.5, we obtain Chatterjea's fixed point theorem [3].

\section{From metric to partial metric}

As we have said in Section 1, partial metric spaces arose from the need to develop a version of the Banach contraction principle which would work for partially computed sequences as well as totally computed ones [23].

In this section, from our previous obtained results on metric spaces, we show that we can deduce easily various fixed point theorems on partial metric spaces including the Matthews fixed point theorem.

Corollary 3.1 Let $(X, p)$ be a complete partial metric space and $T: X \rightarrow X$ be a given mapping. Suppose that for any $0<a<b<\infty$, there exists $0<\gamma(a, b)<1$ such that for all $x, y \in X$,

$$
a \leq p(x, y) \leq b \quad \Longrightarrow \quad p(T x, T y) \leq \gamma(a, b) p(x, y)
$$

Then $T$ has a unique fixed point $x^{*} \in X$. Moreover, we have $p\left(x^{*}, x^{*}\right)=0$.

Proof From (1), for all $x, y \in X$, we have

$$
p(x, y)=\frac{p^{s}(x, y)+p(x, x)+p(y, y)}{2} .
$$

Note that since $(X, p)$ is complete, from Lemma 1.1, $\left(X, p^{s}\right)$ is a complete metric space. Consider the function $\varphi: X \rightarrow[0, \infty)$ defined by

$$
\varphi(x)=p(x, x), \forall x \in X .
$$

Then from (15), for any $0<a<b<\infty$, there exists $0<\gamma(a, b)<1$ such that for all $x, y \in X$,

$$
\begin{aligned}
2 a & \leq p^{s}(x, y)+\varphi(x)+\varphi(y) \leq 2 b \\
& \Longrightarrow \quad p^{s}(T x, T y)+\varphi(T x)+\varphi(T y) \leq \gamma(a, b)\left[p^{s}(x, y)+\varphi(x)+\varphi(y)\right] .
\end{aligned}
$$

Now, $T$ satisfies condition (2) of Theorem 2.1 with $d=p^{s}$. Finally, to apply Theorem 2.1, we have to check the lower semi-continuity of the function $\varphi$ (with respect to the topology of $\left.p^{s}\right)$. Let $\left\{x_{n}\right\}$ be a sequence in $X$ such that $\lim _{n \rightarrow+\infty} p^{s}\left(x_{n}, x\right)=0$, where $x \in X$. Then by Lemma 1.1, we get $\lim _{n \rightarrow+\infty} p\left(x_{n}, x_{n}\right)=p(x, x)$, that is, $\lim _{n \rightarrow+\infty} \varphi\left(x_{n}\right)=\varphi(x)$. Thus, $\varphi$ is continuous and therefore the desired result follows immediately from Theorem 2.1.

Now, the Matthews fixed point theorem follows immediately from Corollary 3.1.

Corollary 3.2 Let $(X, p)$ be a complete partial metric space and $T: X \rightarrow X$ be a given mapping. Suppose that there exists $0<\gamma(a, b)<1$ such that for all $x, y \in X$,

$$
p(T x, T y) \leq \gamma(a, b) p(x, y) .
$$

Then $T$ has a unique fixed point $x^{*} \in X$. Moreover, we have $p\left(x^{*}, x^{*}\right)=0$. 
Now, from our Theorem 2.3, we deduce the following Kannan's fixed point theorem on partial metric spaces.

Corollary 3.3 Let $(X, p)$ be a complete partial metric space and $T: X \rightarrow X$ be a given mapping. Suppose that there exists a constant $\gamma \in(0,1 / 2)$ such that

$$
p(T x, T y) \leq \gamma[p(x, T x)+p(y, T y)]
$$

for all $x, y \in X$. Then $T$ has a unique fixed point $x^{*} \in X$. Moreover, we have $p\left(x^{\prime \prime}, x^{\prime \prime}\right)=0$.

Proof Using the same notations as in the proof of Corollary 3.1, one can show easily from (16) that for all $x, y \in X$, we have

$$
\begin{aligned}
& p^{s}(T x, T y)+p(T x, T x)+p(T y, T y) \\
& \quad \leq \gamma\left[p^{s}(x, T x)+p^{s}(y, T y)+p(x, x)+p(y, y)+p(T x, T x)+p(T y, T y)\right] .
\end{aligned}
$$

So, the result follows from Theorem 2.3 with $d=p^{s}$ and $\varphi(x)=p(x, x)$.

Analogously, from Theorem 2.4, we derive the following Reich's fixed point theorem on partial metric spaces.

Corollary 3.4 Let $(X, p)$ be a complete partial metric space and $T: X \rightarrow X$ be a given mapping. Suppose that there exist $\alpha, \beta, \gamma \in[0, \infty)$, with $\alpha+\beta+\gamma<1$, such that

$$
p(T x, T y) \leq \alpha p(x, y)+\beta p(x, T x)+\gamma p(y, T y)
$$

for all $x, y \in X$. Then $T$ has a unique fixed point $x^{*} \in X$. Moreover, we have $p\left(x^{*}, x^{*}\right)=0$.

Proof From (17), one can show easily that for all $x, y \in X$, we have

$$
\begin{aligned}
p^{s}(T x, T y)+p(T x, T x)+p(T y, T y) \leq & \alpha\left[p^{s}(x, y)+p(x, x)+p(y, y)\right] \\
& +\beta\left[p^{s}(x, T x)+p(x, x)+p(T x, T x)\right] \\
& +\gamma\left[p^{s}(y, T y)+p(y, y)+p(T y, T y)\right] .
\end{aligned}
$$

So, the result follows from Theorem 2.4 with $d=p^{s}$ and $\varphi(x)=p(x, x)$.

From Theorem 2.5, we get the following Chatterjea's fixed point theorem on partial metric spaces.

Corollary 3.5 Let $(X, p)$ be a complete partial metric space and $T: X \rightarrow X$ be a given mapping. Suppose that there exists a constant $k \in(0,1 / 2)$ such that

$$
p(T x, T y) \leq k[p(x, T y)+p(y, T x)]
$$

for all $x, y \in X$. Then $T$ has a unique fixed point $x^{*} \in X$. Moreover, we have $p\left(x^{\prime \prime}, x^{\prime \prime}\right)=0$. 
Proof From (18), one can show easily that for all $x, y \in X$, we have

$$
\begin{aligned}
& p^{s}(T x, T y)+p(T x, T x)+p(T y, T y) \\
& \quad \leq k\left[p^{s}(x, T y)+p^{s}(y, T x)+p(x, x)+p(y, y)+p(T x, T x)+p(T y, T y)\right] .
\end{aligned}
$$

So, the result follows from Theorem 2.5 with $d=p^{s}$ and $\varphi(x)=p(x, x)$.

\section{Competing interests}

The authors declare that they have no competing interests.

\section{Authors' contributions}

All authors contributed equally and significantly to writing this manuscript.

\section{Author details}

'Department of Mathematics, King Saud University, Riyadh, Saudi Arabia. ${ }^{2}$ Dipartimento di Matematica e Informatica, Università degli Studi di Palermo, Via Archirafi 34, Palermo, 90123, Italy. ${ }^{3}$ DEIM, Università degli Studi di Palermo, Viale delle Scienze, Palermo, 90128, Italy.

\section{Acknowledgements}

This work is supported by the Research Center, College of Science, King Saud University.

Received: 7 August 2012 Accepted: 11 December 2012 Published: 8 January 2013

\section{References}

1. Banach, S: Sur les opérations dans les ensembles abstraits et leur application aux équations intégrales. Fundam. Math. 3, 133-181 (1922)

2. Berinde, $V$, Vetro, F: Common fixed points of mappings satisfying implicit contractive conditions. Fixed Point Theory Appl. 2012, 105 (2012)

3. Chatterjea, SK: Fixed point theorem. C. R. Acad. Bulgare Sci. 25, 727-730 (1972)

4. Cirić, LB: A generalization of Banach's contraction principle. Proc. Am. Math. Soc. 45(2), 267-273 (1974)

5. Hadžić, O, Pap, E: Fixed Point Theory in Probabilistic Metric Spaces. Kluwer, London (2001)

6. Kannan, R: Some results on fixed points. Bull. Calcutta Math. Soc. 60, 71-76 (1968)

7. Kannan, R: Some results on fixed points - II. Am. Math. Mon. 76, 405-408 (1969)

8. Matthews, SG: Partial metric topology. In: Proceedings of the 8th Summer Conference on General Topology and Applications. Annals of the New York Academy of Sciences, vol. 728, pp. 183-197 (1994)

9. Mustafa, Z, Sims, B: A new approach to generalized metric spaces. J. Nonlinear Convex Anal. 7(2), $289-297$ (2006)

10. Reich, S: Kannan's fixed point theorem. Boll. Unione Mat. Ital. 4, 1-11 (1971)

11. Suzuki, T: A generalized Banach contraction principle that characterizes metric completeness. Proc. Am. Math. Soc. 136(5), 1861-1869 (2008)

12. Vetro, F: On approximating curves associated with nonexpansive mappings. Carpath. J. Math. 27, 142-147 (2011)

13. Altun, I, Sola, F, Simsek, H: Generalized contractions on partial metric spaces. Topol. Appl. 157(18), 2778-2785 (2010)

14. Aydi, H, Abbas, M, Vetro, C: Partial Hausdor metric and Nadler's fixed point theorem on partial metric spaces. Topol. Appl. 159, 3234-3242 (2012)

15. Aydi, H, Vetro, C, Sintunavarat, W, Kumam, P: Coincidence and fixed points for contractions and cyclical contractions in partial metric spaces. Fixed Point Theory Appl. 2012, 124 (2012)

16. Ćirić, LB, Samet, B, Aydi, H, Vetro, C: Common fixed points of generalized contractions on partial metric spaces and an application. Appl. Math. Comput. 218, 2398-2406 (2011)

17. Oltra, S, Valero, O: Banach's fixed point theorem for partial metric spaces. Rend. Istit. Mat. Univ. Trieste. 36(1-2), 17-26 (2004)

18. Paesano, D, Vetro, P: Suzuki's type characterizations of completeness for partial metric spaces and fixed points for partially ordered metric spaces. Topol. Appl. 159, 911-920 (2012)

19. Romaguera, S: Fixed point theorems for generalized contractions on partial metric spaces. Topol. Appl. 159, 194-199 (2012)

20. Rus, IA: Fixed point theory in partial metric spaces. An. Univ. Vest. Timiş., Ser. Mat.-Inform. 46(2), 141-160 (2008)

21. Samet, B, Rajović, M, Lazović, R, Stoiljković, R: Common fixed point results for nonlinear contractions in ordered partial metric spaces. Fixed Point Theory Appl. 2011, 71 (2011)

22. Vetro, F, Radenović, S: Nonlinear $\psi$-quasi-contractions of Ćirić-type in partial metric spaces. Appl. Math. Comput. 219(4), 1594-1600 (2012)

23. Bukatin, M, Kopperman, R, Matthews, S, Pajoohesh, H: Partial metric spaces. Am. Math. Mon. 116, 708-718 (2009)

doi:10.1186/1687-1812-2013-5

Cite this article as: Samet et al.: From metric spaces to partial metric spaces. Fixed Point Theory and Applications 2013 2013:5 